\title{
A NEW METHOD FOR DETERMINATION OF THE RELIABILITY INDEX OF DISTRIBUTED PARAMETER SYSTEMS
}

\author{
NGUYen VAN Pho \\ Hanoi University of Civil Engeneering
}

\begin{abstract}
In this paper, a method to determine the reliability - index of distributed systems is proposed. By the new method, instead of finding jointly probability depending on multi conditions of inequalities one can find probability depending on only one inequality and no requiring to know jointly density function of basic variables. Therefore, it is very favourable for the calculation of the reliability - index of mechanical systems with distributed parameter.

For illustrating the proposed method, a simple example is considered.
\end{abstract}

\section{Introduction}

In general, mechanical systems are systems with distributed parameters.

The distributed parameter system (DPS) herein means a system of which paramaters depend on space and time variables. Some works have either directly or indirectly referred to the reliability of DPS $[1,2,3, \ldots]$.

Reliability of DPS is a probability depending on multi-conditions of inequalities. It is not easy however to modelize DPS by electrical networks, in order to facilitate the reliability computation.

Consequently, to compute the reliability of DPS, we have to consider the problem of the cross, it is a level in multidimensional space of a stochastic process [4].

Many difficullties are therefore faced.

The quality of a system is shown by several characteristic quantities. If the characteristic quantities satisfy a system of conditions of ensure quality, then the considered system is safety.

In the case, we can find state variables $\mathbf{u}=\left\{u_{i}\right\}$ from the state equation $L \mathbf{u}=\mathbf{q}$, and quality variables from $M \mathbf{u}=\mathbf{v}[1]$, the reliability of DPS is determined by

$$
P_{S}=\text { Prob }\left\{\begin{array}{c}
f_{1}[\mathbf{v}(\mathbf{r}, \mathbf{X})] \geq 0 \\
f_{2}[\mathbf{v}(\mathbf{r}, \mathbf{X})] \geq 0 \\
\cdots \quad \ldots \quad \ldots \\
f_{n}[\mathbf{v}(\mathbf{r}, \mathbf{X})] \geq 0 \\
\forall \mathbf{r} \in V
\end{array}\right\}
$$

where $\mathbf{r}=\left(r_{1}, r_{2}, r_{3}\right)^{T}$ is space variables, 
$\mathbf{X}=\left(X_{1}, X_{2}, \ldots, X_{n}\right)$ - basic random variables,

$V$ - the space area occupied by the system,

$\mathbf{v}=\left\{v_{i}\right\}$ - quality variables.

The probability calculation (1.1) is very difficult. The first, it has not enough basic data for finding jointly density function of basic variables. The second, algorithm to find $(1.1)$ is very complicated.

In this paper, a method to determine reliability index is proposed. The new method is shown that we only find probabilities depending on each inequality, after that select their minimum value. Similarly, for reliability index.

$$
\beta=\min _{\{i\}} \beta_{i},
$$

where $\beta$ - reliability index of DPS,

$\beta_{i}$ - reliability index depending on only each $\mathrm{i}^{\text {th }}$ inequality.

\section{Geometric reliability index and safe probability}

Let $X_{1}, X_{2}, \ldots, X_{n}$ be independent normally distributed variables. The safe condition is $f(\mathbf{X}) \geq 0$, then the safety margin is $M \equiv f(\mathbf{X})$ and the failure surface is $f(\mathbf{X})=0$. The reliability index is defined by

$$
\beta=\frac{\mu_{M}}{\sigma_{M}},
$$

where $\mu_{M}$ and $\sigma_{M}$ are the mean value and standard deviation of $M$.

There exists a one to one relation between the probability of failure $P_{f}$ and the reliability index $\beta$ [5].

$$
P_{f}=\Phi(-\beta) \Leftrightarrow \beta=-\Phi^{-1}\left(P_{f}\right),
$$

where

$$
\Phi(x)=\int_{-\infty}^{x} \frac{1}{\sqrt{2 \pi}} \exp \left(-\frac{1}{2} t^{2}\right) d t
$$

is the standard normal distribution function.

The reliability index $\beta$ is the shortest distance from the origin of normalized space to failure surface $[5,2]$.

Let $p\left(x_{1}, x_{2}, \ldots, x_{n}\right)$ be jointly density function of random variables $X_{1}, X_{2}, \ldots, X_{n}$ and safe condition $f(\mathbf{X}) \geq 0$. The safety probability is

$$
P_{S}=\int_{f(\mathbf{X}) \geq 0} \ldots \int p\left(x_{1}, x_{2}, \ldots, x_{n}\right) d x_{1} d x_{2} \cdots d x_{n} .
$$


And failure probability is

$$
P_{f}=\int_{f(\mathbf{X})<0} \ldots \int p\left(x_{1}, x_{2}, \ldots, x_{n}\right) d x_{1} d x_{2} \cdots d x_{n}
$$

Because $p\left(x_{1}, x_{2}, \ldots, x_{n}\right) \geq 0$, we accept the reasonable property in more general case:

If the safe set $A \subseteq B$, then

$$
P_{S}(A) \leq P_{S}(B) \quad \text { or } \quad P_{f}(A) \geq P_{f}(B),
$$

where $P_{S}(A), P_{S}(B)$ are safe probabilities according to safe domains $A$ and $B$.

From (2.2), we see that

$$
\beta(A) \leq \beta(B) .
$$

\section{Reliability index of DPS}

In this section, we will consider the probability (1.1). At first, we study the probability depending on only one condition

$$
P_{s_{(i)}}=\operatorname{Prob}\left\{f_{i}[\mathbf{v}(\mathbf{r}, \mathbf{X})] \geq 0\right\} .
$$

From now, we will study on the space of normalized random variables.

Let the mean values of $X_{i}(i=1, \ldots, n)$ be $\mu_{X_{i}}$ and the standard deviations $\sigma_{X_{i}}$. Introduce normalized random variables

$$
\begin{aligned}
& X_{i}^{\prime}=\frac{X_{i}-\mu_{X_{i}}}{\sigma_{X_{i}}} \quad i=1,2, \ldots, n \\
& \mu_{X_{i}^{\prime}}=0, \quad \sigma_{X_{i}^{\prime}}=1 .
\end{aligned}
$$

According to (3.2) the failure surface $f(\mathbf{r}, \mathbf{X})=0$ will be transformed into: $F_{i}\left(\mathbf{r}, \mathbf{X}^{\prime}\right)=0$ in the normalized $\left\{X_{i}^{\prime}\right\}$ coordinate system.

The corresponding safe condition is

$$
F_{i}\left(\mathbf{r}, \mathbf{X}^{\prime}\right) \geq 0 .
$$

In view of geometry, the inequality (3.3) determines a $G_{i}$ - domain in $\left\{x_{i}^{\prime}\right\}$ space.

We suppose that $G_{i}$ is a convex domain, filled with the origin of coordinates.

Without the loss of generality, we can take an illustration for argument in a twodimensional case (Fig. 1), $O^{\prime} A=\beta$ 


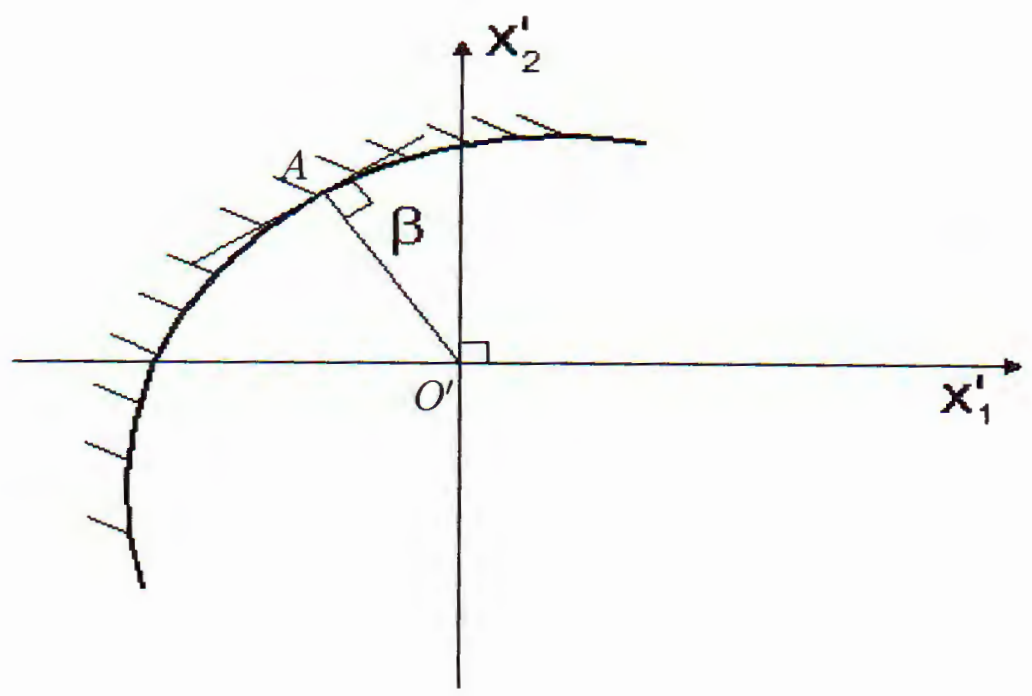

Fig. 1

The case of several conditions is illustrated on Fig. 2

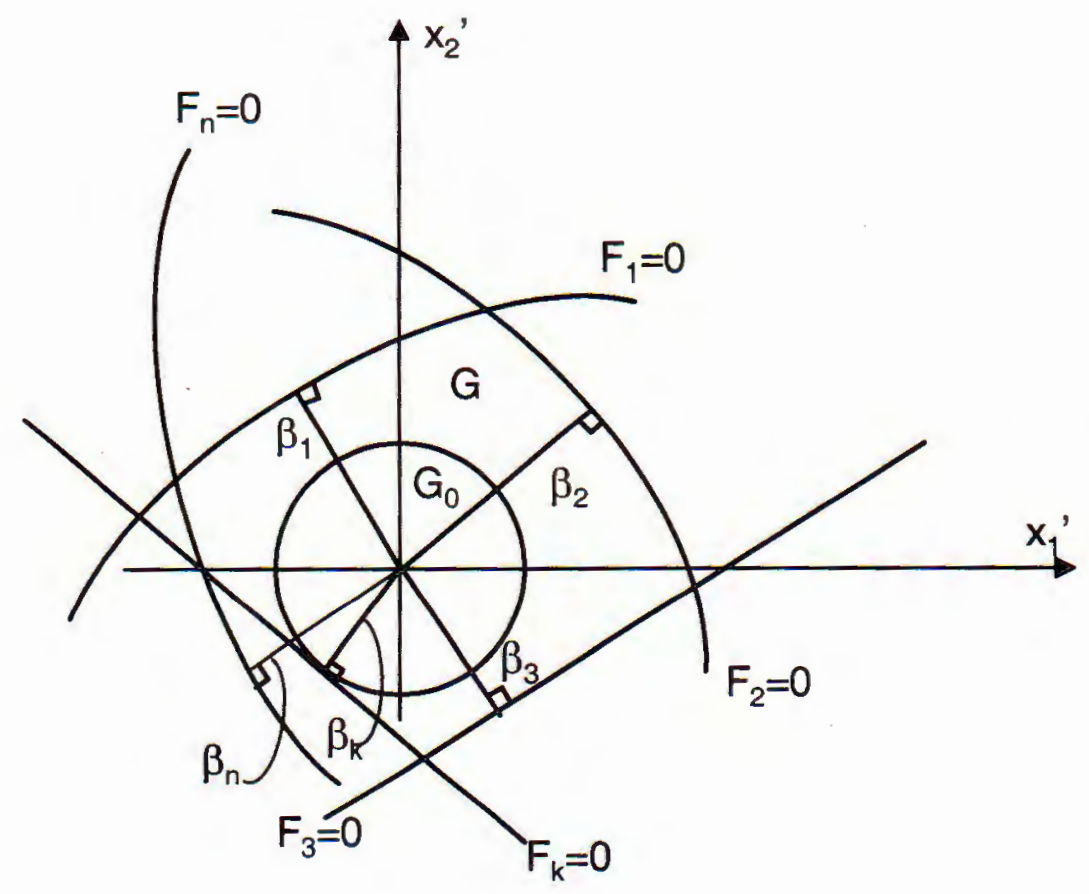

Fig. 2 
and the safe probability is

$$
P_{S}=\text { Prob. } \quad\left\{\begin{array}{c}
F_{1}\left(\mathbf{r}, \mathbf{X}^{\prime}\right) \geq 0 \\
F_{2}\left(\mathbf{r}, \mathbf{X}^{\prime}\right) \geq 0 \\
\ldots \ldots \ldots \ldots \\
F_{k}\left(\mathbf{r}, \mathbf{X}^{\prime}\right) \geq 0 \\
\ldots \ldots \ldots \ldots \\
F_{n}\left(\mathbf{r}, \mathbf{X}^{\prime}\right) \geq 0 \\
\forall \mathbf{r} \in V
\end{array}\right\}
$$

From above discussion, we have

$$
\begin{gathered}
F_{1} \geq 0 \Leftrightarrow G_{1} \rightarrow \beta_{1}\left(G_{1}\right) \\
F_{2} \geq 0 \Leftrightarrow G_{2} \rightarrow \beta_{2}\left(G_{2}\right) \\
\ldots \quad \cdots \quad \ldots \\
F_{n} \geq 0 \Leftrightarrow G_{n} \rightarrow \beta_{n}\left(G_{n}\right)
\end{gathered}
$$

and denote $G \equiv \bigcap_{i=1}^{n} G_{i}$ is the safe domain of system. It is a convex domain.

We can find $\beta_{i}(i=1,2, \ldots, n)$ easily by the linearization method or the iteration method [5], they are the shortest distances from the origin to $G_{i}$.

Let

$$
\beta_{k}=\min _{\{i\}} \beta_{i}
$$

we will prove that $\beta_{k}$ is the probability index of system.

Draw a circle with center at the origin and radius $\beta_{k}$, this circle contacts with failure surface $F_{k}=0$.

The domain determined by

$$
X_{1}^{\prime 2}+X_{2}^{\prime 2} \leq \beta_{k}^{2}
$$

is denoted $G_{0}$.

We clearly see that

$$
\begin{aligned}
& G \subseteq G_{k} \Rightarrow P_{S}(G) \leq P_{S}\left(G_{k}\right), \\
& G_{0} \subseteq G \Rightarrow P_{S}\left(G_{o}\right) \leq P_{S}(G) .
\end{aligned}
$$

According to (2.3), we have:

$$
\begin{aligned}
\beta(G) & \leq \beta_{k}\left(G_{k}\right) \\
\text { and } \quad \beta\left(G_{0}\right) & \leq \beta(G) .
\end{aligned}
$$


But according to geometric definition of Reliability index

$$
\begin{aligned}
\beta_{k}=\beta\left(G_{0}\right)= & \beta \Rightarrow \\
& \beta(G)=\beta_{k}=\min _{\{i\}} \beta_{i} .
\end{aligned}
$$

The proof is completed. The expression (3.5) proves that, for determining reliability index of DPS, we only should find $\beta_{i}-(i=\overline{1, n})$.

\section{Generalization}

The above result can be generalized for the multidimensional case of random variables. In the cases, the state equation $L \mathbf{u}=\mathbf{q}$ has numerical solution only, we can use the proposed method to find $\beta_{k}$ by using linearization method [5].

5. Example.

Calculate reliability index of circular cylindrical tank of constant thickness $h$ with the lower edge built in; it is filled with a liquid of specific gravity $g$ (ton per $\mathrm{m}^{3}$ ) (Fig. 3)

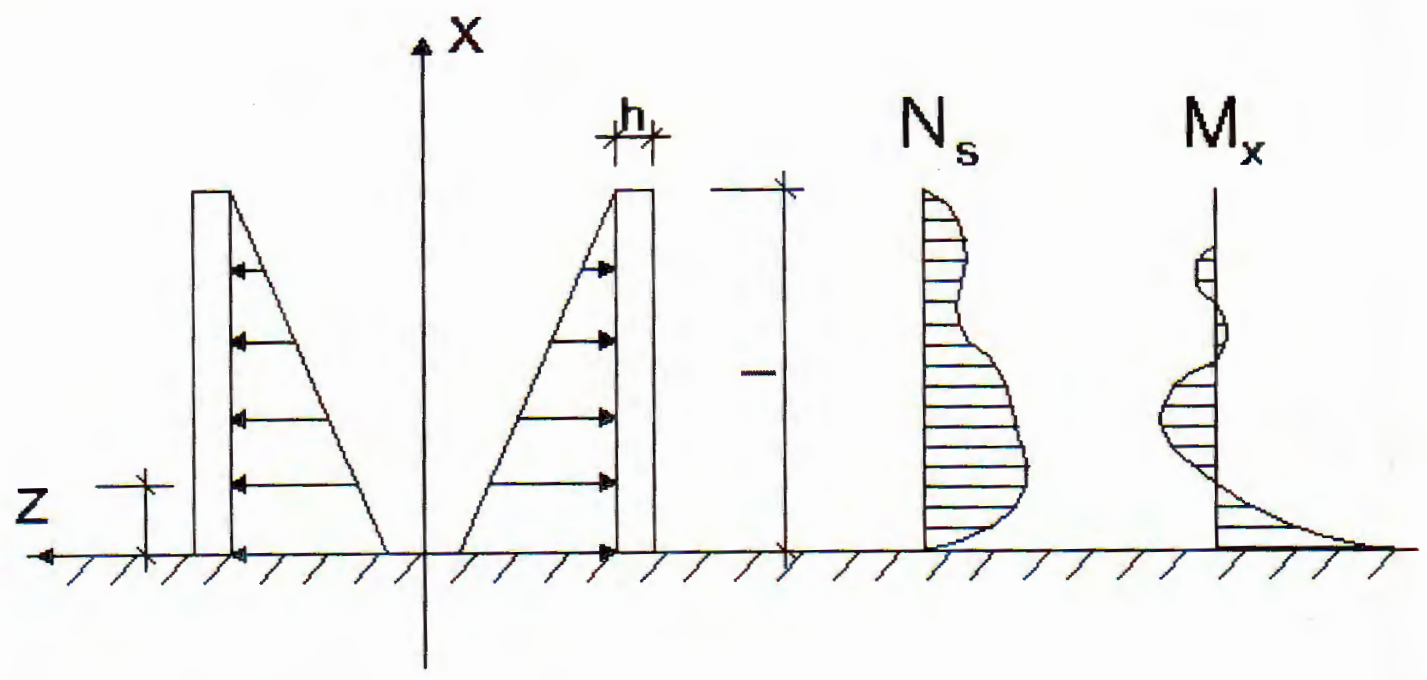

Fig. 3

The pressure at the wall is

$$
z=g(\ell-x)
$$

Differential equation of displacement is of the form [6]

$$
\frac{d^{4} u_{z}}{d x^{4}}+4 \gamma^{4} u_{z}=\frac{g(\ell-x)}{D},
$$


where $\gamma^{4}=\frac{3\left(1-v^{2}\right)}{a^{2} h^{2}}$

The boundary conditions are:

$$
\begin{array}{lll}
\text { at } \quad x=0 ; & u_{z}=0 ; \quad u_{x}=0 ; & \frac{d u_{z}}{d x}=0 \\
\text { at } \quad x=\ell ; & M_{x}=D \frac{d^{2} u_{z}}{d x^{2}}=0 ; \quad Q_{x}=D \frac{d^{3} u_{z}}{d x^{3}}=0 .
\end{array}
$$

The deflection and general stress are

$$
\begin{gathered}
u_{z}=\frac{g a^{2}}{E h}\left\{1-x-e^{-v x}\left[\ell \cos \gamma x+\left(\ell-\frac{1}{\gamma}\right) \sin \gamma x\right]\right\}, \\
N_{S}=C\left(\frac{u_{z}}{a}+\nu \frac{d u_{x}}{d x}\right)=\frac{c\left(1-\nu^{2}\right)}{a} u_{z}, \\
M_{x}=D \frac{d^{2} u_{z}}{d x^{2}}=\frac{g a \ell h}{2 \sqrt{3\left(1-v^{2}\right)}} e^{-\gamma x}\left[\left(1-\frac{1}{\gamma \ell}\right) \cos \gamma x-\sin \gamma x\right], \\
M_{S}=v D \frac{d^{2} u_{z}}{d x^{2}} ; \quad Q_{x}=D \frac{d^{3} u_{z}}{d x^{3}} .
\end{gathered}
$$

The bending moment will be maximum at $x=0$ :

$$
M_{x=0}=\left(1-\frac{1}{\gamma \ell}\right) \frac{g a \ell h}{2 \sqrt{3\left(1-v^{2}\right)}} \text { and axial force } N_{z}=0 .
$$

The safe condition is elastic condition at $x=0$

$$
M_{x=0} \leq M_{e}, \quad M_{e}=\frac{1}{6} \sigma_{0} h^{2},
$$

where $M_{e}$ is a maximum elastic moment

$$
P_{S}=\operatorname{Prob}\left(M_{x=0} \leq M_{e}\right)
$$

or

$$
P_{S}=\operatorname{Prob}\left\{1-\frac{1}{\gamma \ell} \frac{g a \ell h}{2 \sqrt{3\left(1-v^{2}\right)}} \leq \frac{1}{6} \sigma_{0} h^{2}\right\} .
$$

where $\sigma_{0}$ is yield stress. Basic random variables are $\sigma_{\sigma}, a, \ell, h$.

By using the linearization method [5] we can find $P_{S}$.

\section{Conclusions}

The Determination of Reliability index of DPS is a complex problem. The method presented in this paper has given a simple method for the case of a convex safe domain. Some discussions on the Reliability index are presented in $[2,5,3]$. 
This research has been supported by a grant of the Fundamental Research Program in Natural Sciences.

\section{REFERENCES}

1. Bolotin V. V. Probability methods and reliability theory in the calculation of structures - Moscow - 1982 (in Russian).

2. Ditkevsen 0., Madsen H. 0. Structural reliability methods. John wiley - Sons 1996.

3. Nguyen Van Pho. Reliability index of distributed parameter system. Vietnam Journal of Mechanies Vol 22. No 4-2000.

4. Tikhonov V. I. The cross a leved of the stochastic process. Science Publishers. Moscow 1970 (in Russian).

5. Palle Thoft - Christensen, Yoshisada Murotsu. Application of Structural Systems Reliability theory. Springer - Verlag. Berlin Heidelberg New York Tokyo - 1986.

6. Rekach V. G. Static theory of thin Walled space strustures. Mir Publishers, Moscow 1978.

Received May 14, 2003

\section{MỘT PHƯONG PHÁP MỚI XÁC ĐINH CH'̉ SỐ ĐÔ̂ TIN CẬY CỦA HÊ PHÂN BỐ THAM SỐ}

Trong bài báo này, tác giả trình bày một phương pháp mới xác định chỉ số độ tin cậy của hệ phân bố tham số. Theo phương pháp này ta chuyển từ việc tìm một xác suất đồng thời phụ thuộc nhiều bất đẩng thức về tìm các xác suất phụ thuộc một bất đẳng thức. Đó là điều vô cùng thuận lợi cho việc tính độ tin cậy của hệ phân bố tham số, mặt khác không đòi hỏi biết hàm mật độ phân bố đồng thời.

Để minh họa cho phương pháp nêu ra, bài báo xét một thí dụ đơn giản. 